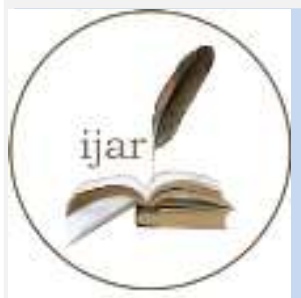

ISSN NO. $2320-5407$

\section{Journal Homepage: - www.journalijar.com} INTERNATIONAL JOURNAL OF ADVANCED RESEARCH (IJAR)

ArticleDOI: $10.21474 /$ IJAR01/6761

DOI URL: http://dx.doi.org/10.21474/IJAR01/6761
LNTENATHaket NeERAt of ADEA

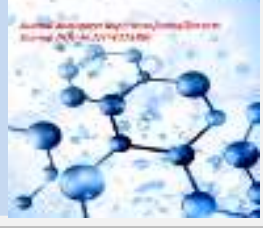

RESEARCH ARTICLE

\title{
DYNAMIC MODEL FOR MOTIVATION AND ACHIEVEMENT TO MATHEMATICS STUDENTS
}

Fitrah Sari Wahyuni Harahap, Herman Mawengkang and Sawaluddin Nasution.

Departement of Mathematics, Universitas Sumatera Utara, Medan 20155, Indonesia.

\section{Manuscript Info}

...........................

Manuscript History

Received: 16 January 2018

Final Accepted: 18 February 2018

Published: March 2018

Key words:-

dynamics model, motivation, achievement, student mathematics.

\section{Abstract}

Dynamic models are used to describe the components of systems that have interesting dynamic behavior. Dynamic models can be described in the form of state diagrams and sequence diagrams. The purpose of the dynamics model is to detect and supply methods for object models. Dynamic model can be used to describe the interrelation between motivation and achievement to mathematics students in the form of object diagram. The determinants of learning motivation and factors in the achievement of the mathematics students will be described as objects in the dynamic model so that this model can be used as a reference and reference to improve the achievement of students' achievement of mathematics.

Copy Right, IJAR, 2018,. All rights reserved.

\section{Introduction:-}

One of the indicators of quality education is the acquisition of maximum learning outcomes from students, whether the learning outcomes in the form cognitivee, affective, and psychomotoric. Student learning outcomes are very influenced by the activities of teaching and learning process in which there are several factors that are determinant of whether or not the activities of teaching and learning process. These factors include:

1. Instruments input, namely: curriculum, library, teachers, facilities, and infrastructure.

2. Raw input, namely: students, motivation, and how to learn students.

3. Environment input, namely: the physical and socio-cultural environment.

In the process of learning to teach, motivation is one factor that is suspected of great influence on learning outcomes. Students with high motivation are expected to obtain good learning outcomes. The importance of student learning motivation is formed, among others, to change the learning to a more positive direction.

Similarly, when we see in the process of learning to teach math. Students who have a high motivation in learning mathematics will do learning activities faster than students who are less motivated in learning. Students who have high motivation in learning mathematics then achievement will also be better.

The dynamic model is required to see how the learning motivation and achievement student achievement. Dynamic models not only refer to important factors that explain variations in the effectiveness of educational purses, but also try to explain why these factors are important by integrating different theoretical orientations into effectiveness. In this way, teachers and other school stakeholders involved in sequence diagram the improvement effort can be wellinformed of the empirical support for the factors involved in their project and the way these factors are oriented within the conceptual framework. 
The development of dynamic models is based on the results of a critical review of the main inventions of EER (Educational Effectiveness Research) and critical analysis of integrated models (Bert Creemers and Leonidas Kyriades, 2015). This model seeks to provide a comprehensive description of the effectiveness of education by referring to factors operating at different levels such as students, classes, schools, and systems that influence student learning outcomes of mathematics.

In this research we will use dynamic model to describe the relevance between the determinants of students learning motivation and the achievement of the mathematics students in the form state diagrams and sequence diagrams. For state diagrams each object will be described with an important dynamic behavior. While the describes the interaction between objects.

Method:-

Determination of dynamic models for motivation and achievement on students' math is done by determining the factors that influence motivation, the factors that determine the achievement to students of mathematics, and the interconnections between all these factors. This research is an analysis of the studies that have been done previously and is a research literature in the field of education. The research steps that will be carried out are as following:

1. Determine the factors that influence the motivation of students learning mathematics Determining the factors of this problem is done by taking into account the extrinsic and intrinsic factors that influence the motivation of students learning mathematics.

2. Determine the factors that affect the achievement mathematics student learning results Determining the factors of this problem is made by considering the internal and external elements that determine the achievement of the mathematics students.

3. Determine the dynamic model for motivation and achievement mathematics student learning outcomes Determining the dynamic model of the factors of achievement mathematics student learning outcomes using state diagrams and sequence diagrams. 


\section{Result:-}

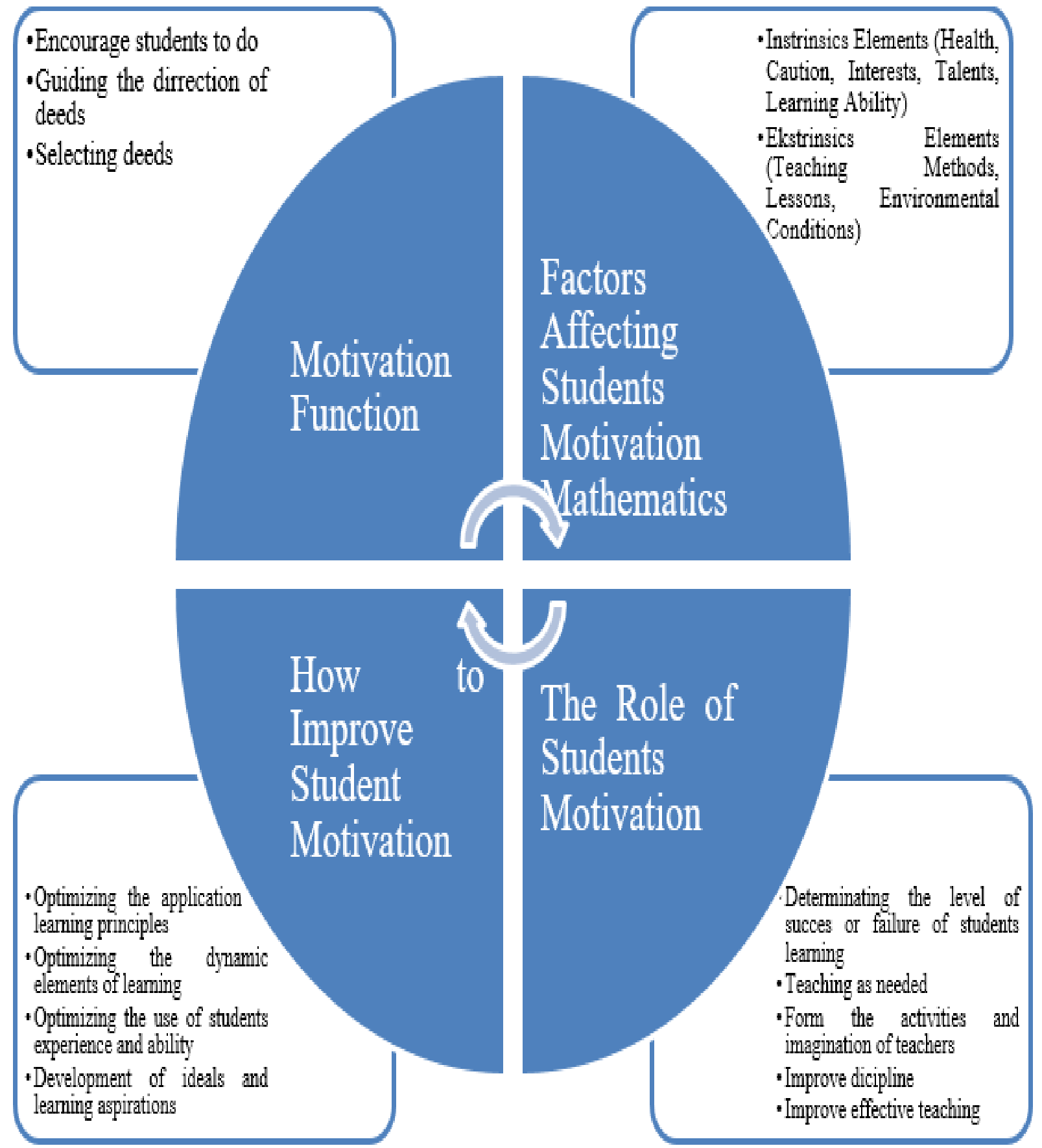

Figure 1:- Factors Influencing the Motivation of Mathematics Students 


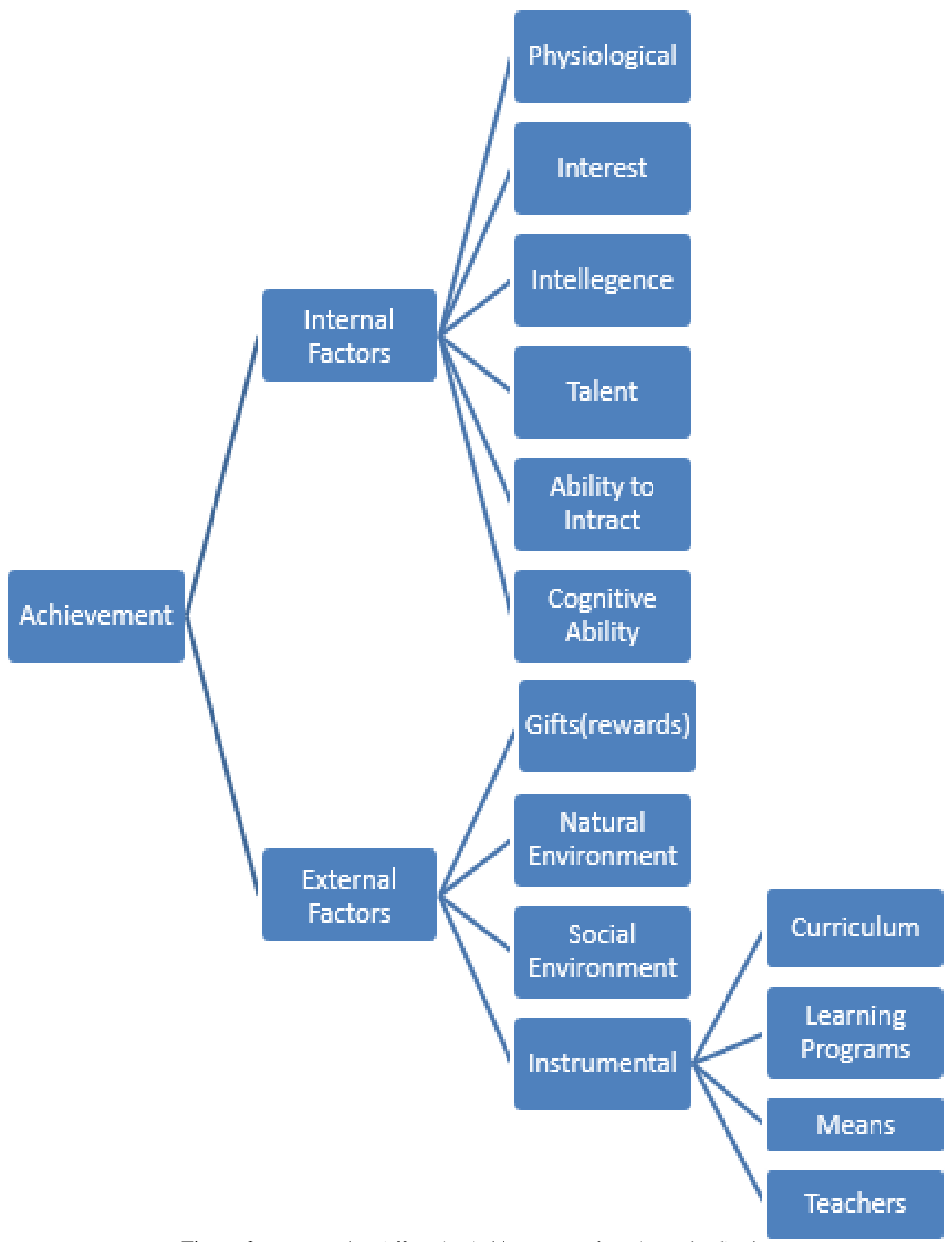

Figure 2:- Factors that Affect the Achievement of Mathematics Students 


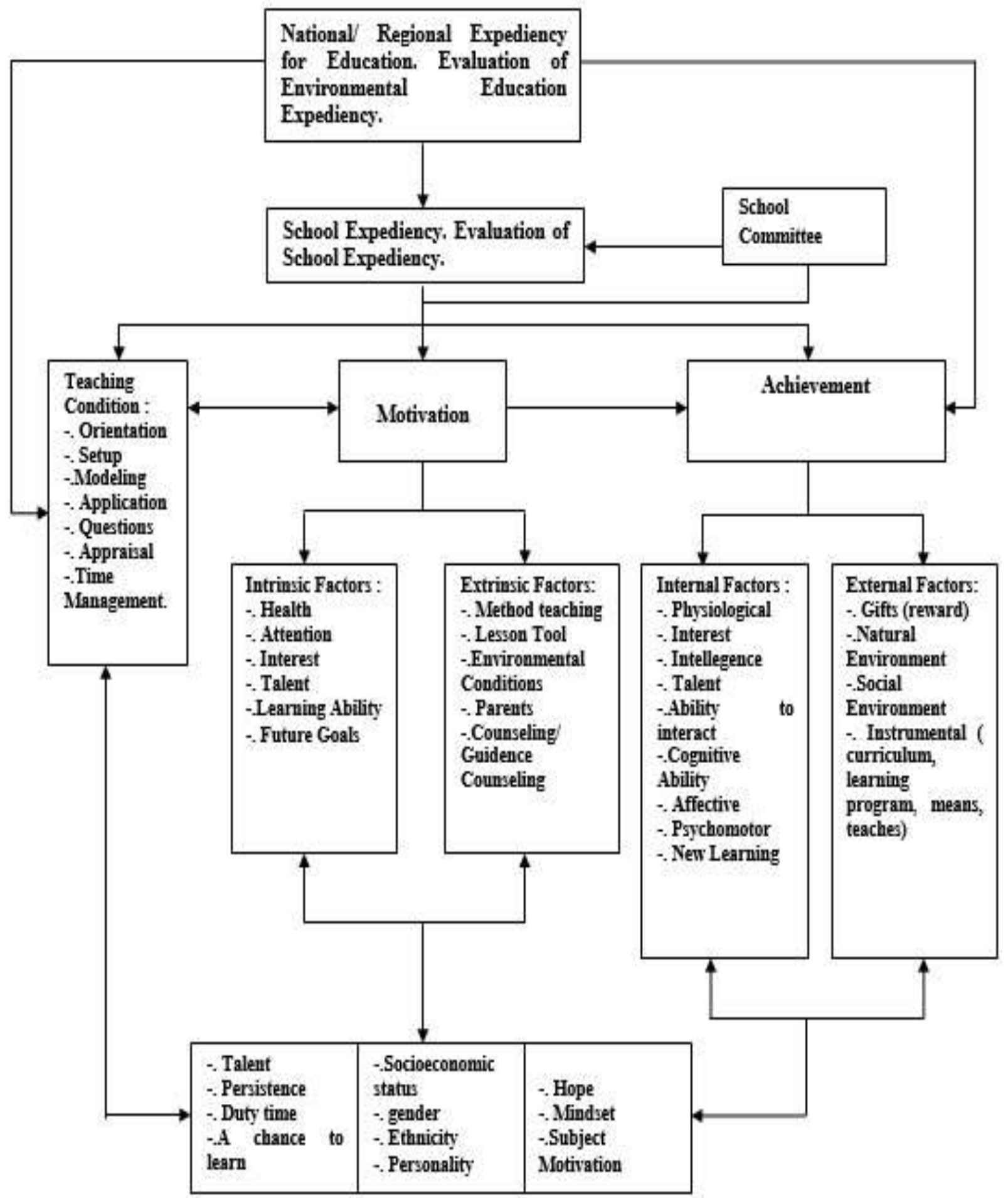

Figure 3:- State Motivation Diagram and Achievement Students Mathematics 

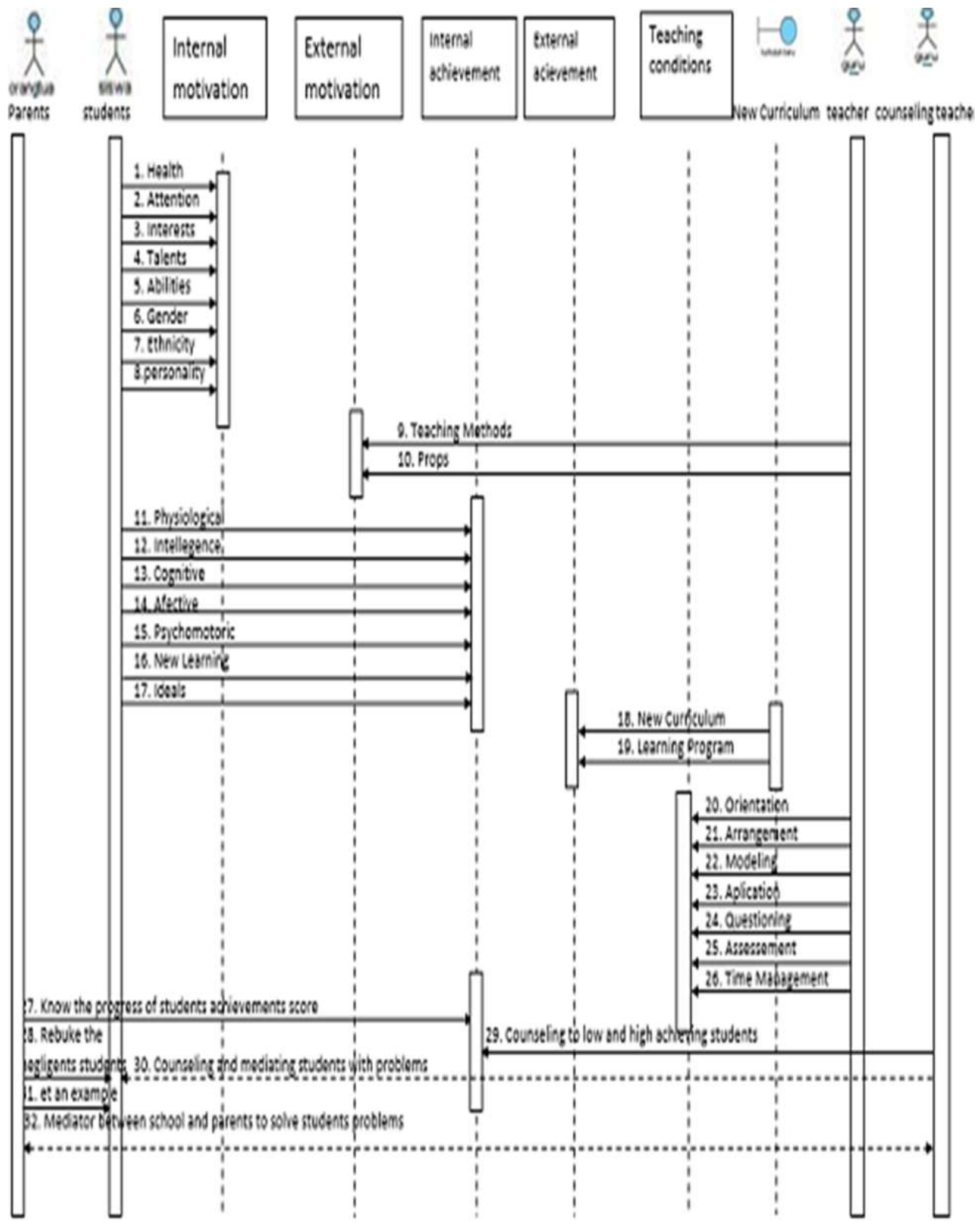

Figure 4:- Sequence Diagram Motivation and Achievement Mathematic Students 


\section{Discussion:-}

1. Diagram of factors that influence the motivation of students learning mathematics

Determining the factors of this problem is done by taking into account the extrinsic and intrinsic factors that influence the motivation of students learning mathematics.

2. Diagram of factors that influence the achievement mathematics student learning outcomes

Determining the factors of this problem is done by considering the internal and external elements of the mathematics students.

3. Dynamic Model for Motivation and Achievement of Mathematics Students

a. State Diagram Motivation and Achievement of Mathematics Students

State diagram of motivation and achievement mathematics students describe a relationship of mutual influence between the educational environment policy evaluation, policy evaluation of the school, teaching conditions, elements of intrinsic and extrinsic motivation, and achievement in the form of internal and external achievement.

b. Sequence Diagram Motivation and Achievement Mathematic Students

Sequence diagrams describe scenarios or series of steps in response of an event to produce a particular output. This diagram is used to show the interaction between objects in ordered commands so that we can know the flow of activity events motivation and achievement students' mathematics.

\section{Conclusion:-}

Dynamic model for motivation and achievement on mathematics students used in this study are state diagrams and sequence diagrams. Both diagrams are easy to understand to illustrate the relationship between motivation and achievement of mathematics students' achievement. The state diagram is not represented for all classes, only those that have a number of well-defined states and class conditions changed by different states. In the actors' behavior diagram sequence (student, parent, teacher of mathematics subjects and teacher counseling) can be clearly described showing the sequence of interactions that occur in each object (teacher, student, curriculum, motivation, and achievement) in the system. The dynamic model of this study is described as follows: 


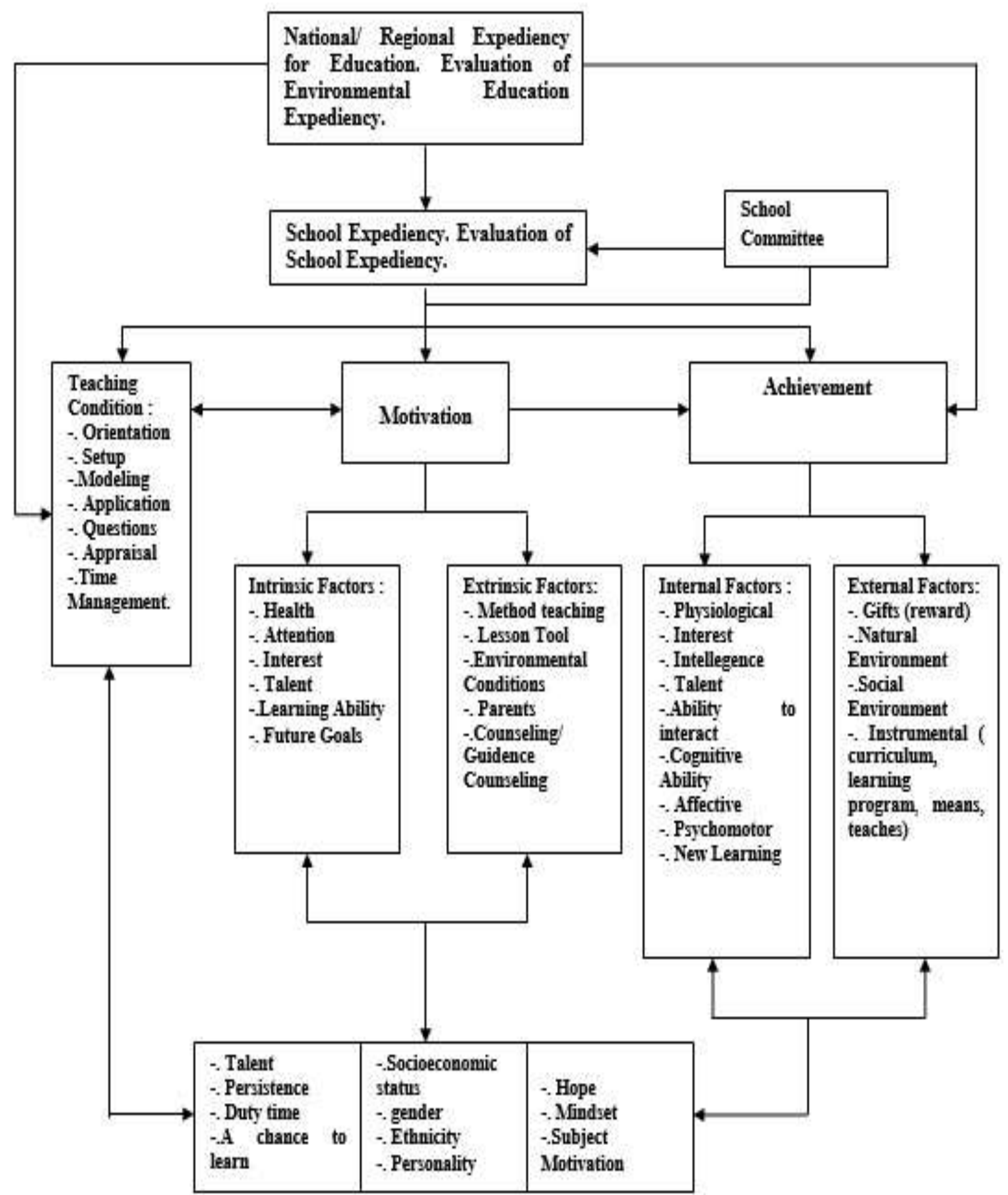

Figure 3:- State Motivation Diagram and Achievement Students Mathematics 


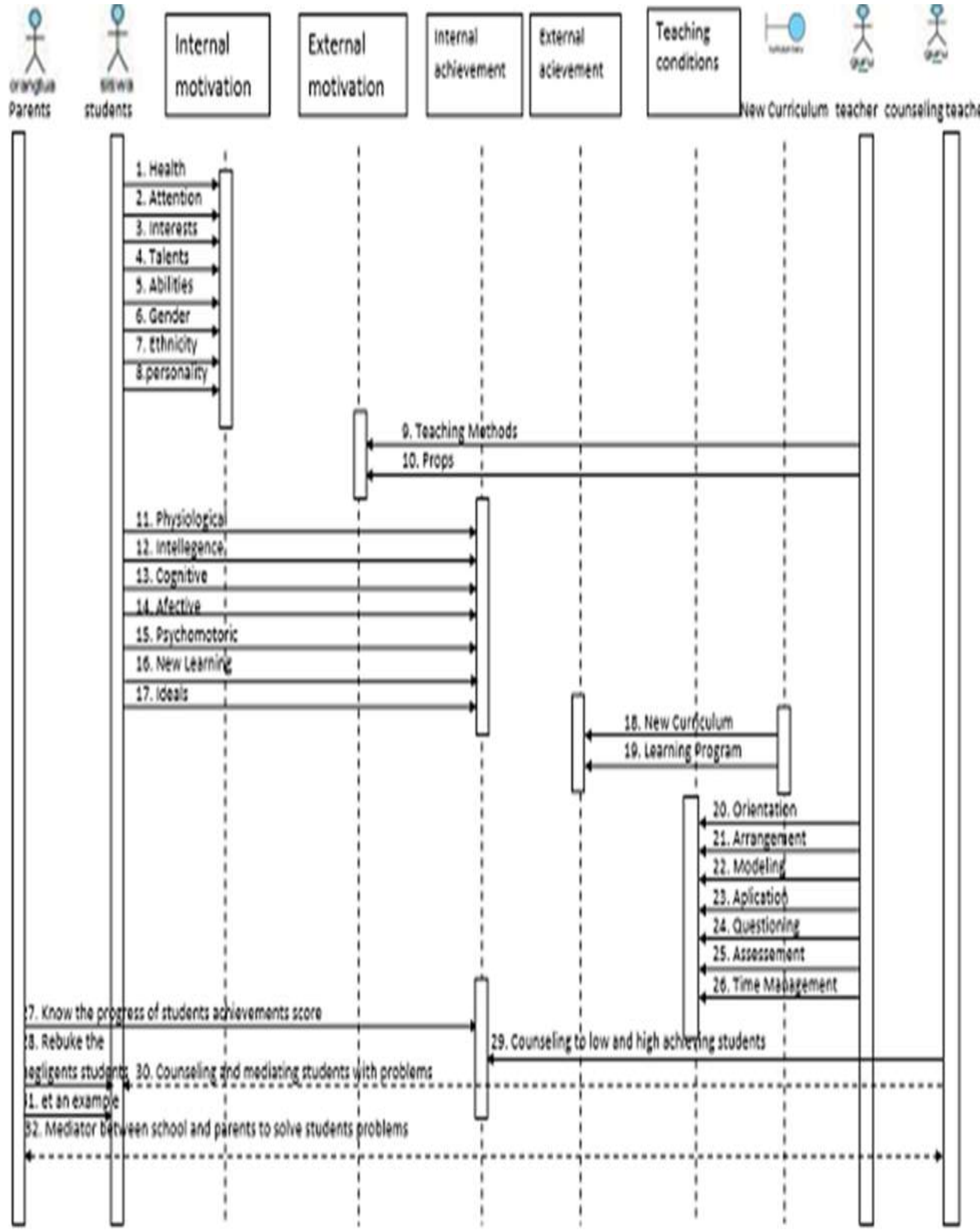

Figure 4:- Sequence Diagram Motivation and Achievement Mathematic Students 
From the two dynamic models obtained expected this model can be used as reference and reference to improve achievement students of mathematics. Researchers hope this final task can be a source of information and reference for other researchers who will conduct a dynamic model research with discussion in the field of education. Shortcomings in this study should be a consideration for other researchers who want to do research in the field of education and others.

\section{Acknowledgements:-}

This is a thesis research, thanks to supervisors and related parties who have been concerned to provide input for the development of this research.

\section{References:-}

1. Barton,P.I., Dynamics Modelling and Simulation. Introduction Industrial Experience with Dynamic Simulation. Massachussets Institute of Technology Cambridge,MA : Departement of Chemical Engineering.

2. Bruegge, B. Dynamic Modeling. Software Engineering 1, Lecture 10. Applied Software Engineering.

3. Creemers, B.P.M., dan Kyriakides,L.(2010). Using the Dynamic Model to Develop An Evidence- Based and Theory- Driven. Approach To School Improvement. Irish Educational Studies. 29 : 1, 5-23.

4. Creemers, B.P.M., dan Kyriades,L.(2015). Developing, Testing, and Using Theoritical Models for Promoting Quality in Education. School Effectiveness and School Improvements. 26 : 1, 102-119.

5. Dawkins,L.D.,(2017). Factors Influencing students achievments in Reading. Walden University: College of Eduction.

6. Direktorat Jenderal Pembelajaran dan Kemahasiswaan Kementerian Riset, Teknologi, dan Pendidikan Tinggi Republik Indonesia.,(2015). Kerangka Kualifikasi Nasional Indonesia.Dokumen 001.RISTEKDIKTI.

7. Herges,R.M.,et al.(2017). Motivation and Achievement of Middle School Mathematics Students. The Mathematics Educator. Volume 26, No.1, 83-106.

8. Kyriakides,L.,et al.(2014). Fourth Meeting of the EARLI SIG Educational Effectiveness. Promoting Student Learning Outcomes in Socially Disadventaged Schools. The Impact of The Dynamic Approach To School Improvement. University of Cyprus.

9. Lassnig,L.(2015). Competence- based education and educational effectiveness. A Critical Review of the research literature on outcome- oriented policymaking in Education.

10. Panayiotou, A. (2015).Doctor of Phylosophy Dissertation. Factors Promoting Quality of Education at Classroom and School level : A European Effectiveness Study in Mathematics and Sciences. University of Cyprus

11. Penninckx, M., Vanhoof, J. Dan Petegem,P.V.(2014). Evaluating The Effectiveness of a Profesional Development Programme on Pupil Well-being in Primary Schools. Studia Paedagogica. Volume 19,n.4.

12. Vanlaar, Gudrun,et al.(2015). Do the teacher and school factors of the dynamic model affect high- and lowachieving student groups to the same extent? Across- country sudy. Research Papers in Education. Univercity of Cyprus. 